\title{
A Review on Welding Residual Stress Measurement by Hole Drilling Technique and its Importance
}

\author{
R. Chakrabarti*, , P. Biswas**, and S. C. Saha*** \\ *Mechanical Engineering Department, Tripura Institute of Technology, Narsingarh, Agartala, 799009, India \\ **Mechanical Engineering Department, Indian Institute of Technology Guwahati, Guwahati, 781039, India \\ ***Mechanical Engineering Department, National Institute of Technology Agartala, Agartala, 799046, India
}

†Corresponding author : pankaj.panu012@gmail.com

(Received March 20, 2018 ; Revised April 25, 2018 ; Accepted May 25, 2018)

\begin{abstract}
Welding residual stress is considered as one of the most responsible factors by the experts for premature failure of the in-service welded structures. Between tensile residual stress and compressive residual stress, while the former type is found to have detrimental effect on the welded part, compressive stress may adhere to some benefits in many cases. It is, therefore, very important to evaluate the welding residual stress in a welded component properly so that suitable measures can be adopted to get the optimized service life of the fabricated structure. The measurement techniques of welding residual stress have been classified into different categories, significantly in destructive and non-destructive in nature. The hole drilling technique is one of the destructive methodologies to measure the welding residual stress using strain gauges which is standardized by ASTM E- 837 and frequently used in the applied field. In this review paper, an effort has been given to understand the fundamentals of the hole drilling method based on extensive literatures' study which reflects the chronological developments of this technique in the field of stress measurement. This paper, further, describes the influence of different operational parameters associated with the hole drilling technique on the outcome of the process.
\end{abstract}

Key Words : ASTM E-837, Residual stress, Destructive method, Hole drilling method, Strain gauge

\section{Introduction}

Welding residual stress or locked-in stress is the stress, which exists in the welded structure after the all external loads are removed. In general, the welding residual stress and related distortion in the plates are dominated by uneven metal deformation, either through contraction or expansion, mainly in the heat affected zone (HAZ) and nearby area of the weld joint, as a result of heating and cooling effect of welding cycle. This is further influenced by the temperature dependent thermo-physical and mechanical properties of materials in use such as specific heat, thermal conductivity, density, thermal expansion coefficients andyield strength of the material ${ }^{1}$. The welding residual stresses are classified as longitudinal stresses and transverse stresses depending on the direction of the stress magnitude with respect to the weld line, while alternatively it can also be classified as tensile and compressive stresses ${ }^{2}$, depending on the nature of the stress developed in the welded part. Significantly, residual stresses may also be categorized as macro \& micro residual stresses, based on the characteristic length, $1_{0}$, which is the length considered for maintaining equilibrium condition of the stresses. Macro residual stresses are the long range stresses (type-I) where polycrystalline or multiphase nature of the material is ignored. Micro residual stresses are described as the type-II and type-III stresses where the former one acts over a number of grain dimensions (3-10 x grain size) \& the later one exits within a grain ( $\leq$ grain size), developed by dislocations and point defects ${ }^{3,4)}$. Between the tensile \& compressive residual stresses, tensile residual stress has detrimental effect on the welded part while the later one may contribute benefits in many cas$\mathrm{es}^{5)}$. Welding residual stresses influence the factors af- 
fecting the weld-joint like fatigue life, corrosion resistance (stress corrosion cracking), brittle structure (hydrogen embrittlement) etc. which ultimately reduce the service life cycles of the component in multicycle fatigue $(\mathrm{N}>106$ cycles) ${ }^{6}$. It has been observed by different researchers that the heat input during welding process acts as a prime source for such stresses where local heating \& cooling of metal with differential cooling rate, related differential plastic flow of molten metal and phase transformations of the grains with volume changes during cooling etc. in a combined way develop welding residual stresses ${ }^{7)}$.

\section{Welding residual stress measurement techniques}

There are different measurement techniques to evaluate the welding residual stress in a welded component and mainly, all established methods are classified into two main categories ${ }^{1-3,6)}$ viz. a) Analytical methods and b) Experimental Methods and the later one is further classified as Destructive \& Non-destructive, based on the nature of the measurement procedure.

\subsection{Analytical method}

The use of analytical method for calculating the welding residual stress in metal plates has been appreciated by different researchers for its simplified approach which can be adopted as an approximation for further analysis. A theoretical model, in connection with this, was proposed by Koichi Masubuchi and D. C. Martin ${ }^{8)}$ by an empirical relationship, as stated in the equation no.1, based on modified parabolic stress distribution where the distribution of longitudinal stress with respect to the weld line was considered.

$$
\sigma_{x}=\sigma_{\max }\left[1-(y \div b)^{2}\right] \times \exp \cdot\left[-0.5(y \div b)^{2}\right]
$$

In this expression, longitudinal residual stresses, $\sigma_{\mathrm{x}}$, has been approximated on $\mathrm{Y}$-axis along $\mathrm{X}$-axis putting the value of the yield stress of the weld metal $\left(\sigma_{\max }\right)$ and the width of HAZ (b) from the weld centre line. Furthermore, the width of HAZ (b) from the weld centre line can be obtained from the another relationship as stated in the equation no.2, as derived by Adams ${ }^{3)}$ and the same can be experimentally measured using suitable chemical etching on the properly prepared specimen through macroscopic study.

$$
1 /(T p-T o)=\{(4.13 \times \rho \times c \times t \times y) \div H\}+\{1 \div(T m-T o)\}
$$

In the stated relationship, $T p$ stands for Eutectoid temperature (i.e. $723^{\circ} \mathrm{C}$ for steel) of the weld metal at a certain distance from the weld line, To indicates the initial temperature of the plate, $\rho$ is the density of the parent metal, $c$ is the specific heat, $t$ is the thickness of the plate in use, $y=y_{H A Z}$ i.e. the distance from the weld center line, $H$ is the welding heat input and $T m$ is the melting temperature of the plate.

\subsection{Experimental method}

Though, destructive \& non-destructive type measurement approaches are included in this group but all possible varieties of measurement techniques are not equally effective. Some mostly used destructive stress measurement techniques are a) Sectioning Method ${ }^{2,3,9)}$ b) Contour Method ${ }^{10,11)}$ c) Hole-drilling Method ${ }^{1,2,3)}$ d) Slitting method $^{12,13)}$ e) Ring core Method ${ }^{14,15)}$ etc. Nowadays, several advanced non-destructive techniques like X-ray diffraction (XRD) technique ${ }^{16,17)}$, Neutron diffraction technique $^{18,19)}$, Ultrasonic technique ${ }^{20,21)}$, Positron annihilation spectroscopic technique (PAS) ${ }^{22)}$, Barkhausen noise method $^{23,24)}$ etc. are equally adopted in the applied field to measure the welding residual stress. In connection with this, a comparative statement has been summarized in the following table (Table 1) to understand the advantages and disadvantages of different residual stress measurement techniques.

\section{Hole-drilling(straingauge) method}

\subsection{Theory of hole drilling method}

The hole drilling technique is one of the most commonly used methods for the measurement of residual stresses, in the industries as well as in academic field, which is less expensive, reliable in nature \& standardized by ASTM E- $837^{25,26)}$. This technique is fundamentally divided into two categories viz. a) through hole drilling and b) incremental hole drilling and both are standardized by ASTM E-837. In case of through hole drilling process, a suitable hole is drilled in the specimen and the corresponding relieved strain is measured after completion of the drilling process. When incremental hole drilling is considered, the drilling of the hole is done at small increments with equal depth and relieved strain is recorded after each increment. Here, different calibration constants are considered for each of the increments. The fundamental of the hole drilling technique is based on the evaluation of two principal stresses $\left(\sigma_{1}\right.$ and $\left.\sigma_{2}\right)$ from the mathematical relationship between normal stresses $\left(\sigma_{\mathrm{x}}\right.$ and $\left.\sigma_{\mathrm{y}}\right)$ and shear stresses $\left(\tau_{\mathrm{xy}}, \tau_{\mathrm{yx}}\right)$ with respect to a particular plane, when bi-axial stresses are in consideration. The relationship can be defined with the following expression, as stated in the equation no. 3 and equation no. $4^{27)}$, where $\sigma_{1}$ and $\sigma_{2}$ are maximum and minimum principal stresses respectively. 
Table 1 Some residual stress measurement techniques-advantages and disadvantages

\begin{tabular}{|l|l|l|}
\hline \multicolumn{1}{|c|}{ Techniques (Destructive) } & \multicolumn{1}{|c|}{ Advantages } & \multicolumn{1}{c|}{ Disadvantages } \\
\hline Sectioning Method & $\begin{array}{l}\text { Range of materials is broad, } \\
\text { Economic, fast and simple process }\end{array}$ & Limited strain resolution, Less accuracy \\
\hline Contour Method & $\begin{array}{l}\text { Range of materials is large, High-resolution } \\
\text { maps can be developed }\end{array}$ & $\begin{array}{l}\text { Criticality in sample preparation, Complex } \\
\text { approach }\end{array}$ \\
\hline Hole-drilling Method & $\begin{array}{l}\text { Simple and fast process, Widely used, Range } \\
\text { of materials is broad, ASTM standardized } \\
\text { (ASTM E 837) }\end{array}$ & Less resolution, Limited strain sensitivity \\
\hline Ring-core Method & Larger surface strain can be measured & $\begin{array}{l}\text { Specimen damage is more due to complexannular } \\
\text { slot, less convenient, less used }\end{array}$ \\
\hline \multicolumn{1}{|c|}{ Nondestructive } & \multicolumn{1}{c|}{ Disadvantages } \\
\hline X-ray diffraction technique & $\begin{array}{l}\text { Range of materials is large, Macro and micro } \\
\text { residual stress can be measured }\end{array}$ & $\begin{array}{l}\text { Less amount of penetration, Less area covered, } \\
\text { Non-standardized, Not suitable for coarse grain, } \\
\text { Data interpretation is complex }\end{array}$ \\
\hline Neutron diffraction technique & $\begin{array}{l}\text { High penetration ability, High resolution,3D } \\
\text { mapping is possible, High accuracy, Macro } \\
\text { and micro residual stress can be measured }\end{array}$ & High cost, Specialized facility is required \\
\hline Ultrasonic technique & $\begin{array}{l}\text { Fast process, Low cost, Portable, Easily } \\
\text { available }\end{array}$ & $\begin{array}{l}\text { Low resolution, Low deviation in signal with } \\
\text { change in stress }\end{array}$ \\
\hline $\begin{array}{l}\text { Positron annihilation } \\
\text { spectroscopic technique }\end{array}$ & $\begin{array}{l}\text { High penetration ability, High } \\
\text { accuracy,Microstructure - sensitive }\end{array}$ & $\begin{array}{l}\text { Critical set-up, High cost, Specialized facility, } \\
\text { Non-availability }\end{array}$ \\
\hline Barkhausen noise method & $\begin{array}{l}\text { Fast process, Very high Penetration, Micro- } \\
\text { structure - sensitive, No direct contact, sub- } \\
\text { surface stress can be measured }\end{array}$ & $\begin{array}{l}\text { Limited to ferromagnetic } \\
\text { Materials, Proper signal identification is needed } \\
\text { using amplification \& filter. }\end{array}$ \\
\hline
\end{tabular}

$$
\begin{aligned}
& \sigma_{1}=\frac{\left(\sigma_{x}+\sigma_{y}\right)}{2}+\sqrt{\left(\frac{\sigma_{x}-\sigma_{y}}{2}\right)^{2}+\left(\tau_{x y}\right)^{2}} \\
& \sigma_{2}=\frac{\left(\sigma_{x}+\sigma_{y}\right)}{2}+\sqrt{\left(\frac{\sigma_{x}-\sigma_{y}}{2}\right)^{2}+\left(\tau_{x y}\right)^{2}}
\end{aligned}
$$

Using the concept of equilibrium of forces, the stated expressions (i.e. equation no.3\&4) have been derived using Mohr's circle diagram as shown in the Fig. 1. In Mohr's circle diagram, the principal stresses $\left(\sigma_{1}\right.$ and $\sigma$ 2) and normal stresses $\left(\sigma_{\mathrm{x}}\right.$ and $\left.\sigma_{\mathrm{y}}\right)$ have been plotted on the abscissa, considering tensile stress as positive and compressive stress as negative. Correspondingly, the shear stresses $\left(\tau_{\mathrm{xy}}, \tau_{\mathrm{yx}}\right)$ and the principal shear stress $\left(\tau_{\max }\right)$ are plotted on the ordinate, considering the clockwise rotation of the element under shear stress as positive

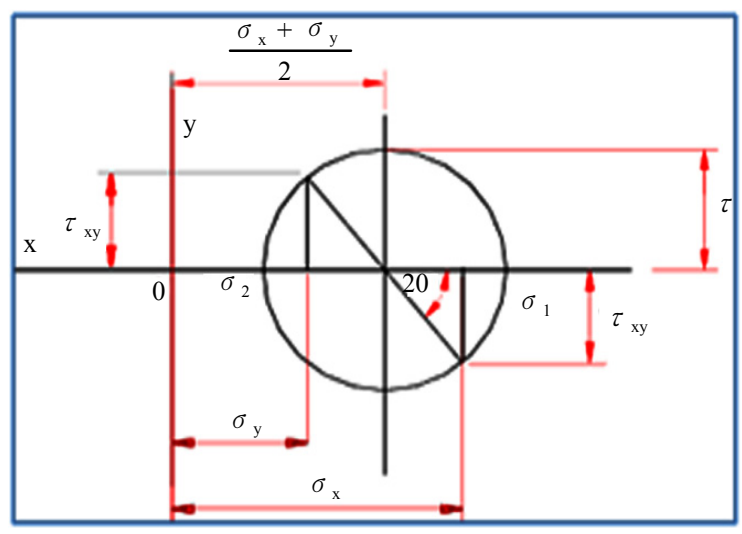

Fig. 1 Mohr's circle and anticlockwise rotation of the element as negative ${ }^{27)}$. From the following expressions, as stated in the equation no.5 and equation no. 6 respectively, the principal stresses are evaluated from Mohr's circle.

$$
\begin{aligned}
& \sigma_{1,2}=\frac{\left(\sigma_{x}+\sigma_{y}\right)}{2} \pm r \\
& r=\sqrt{\left(\frac{\sigma_{x}-\sigma_{y}}{2}\right)^{2}+\left(\tau_{x y}\right)^{2}}
\end{aligned}
$$

From the following elementary equation, as stated in equation no.7, the values of two normal stresses $\left(\sigma_{\mathrm{x}}\right.$ and $\left.\sigma_{\mathrm{y}}\right)$ and shear stress $\left(\tau_{\mathrm{xy}}\right)$ can be obtained putting the values of included angle of strain gauges (i.e. $\theta=0^{0}$, $\left.90^{\circ}, 225^{\circ}\right)$ in the equation. The orientation of strain gauges is shown in Fig. 2 where strain gage no. 1 is parallel to the weld centre line.

$$
\sigma_{1}=\frac{\left(\sigma_{x}+\sigma_{y}\right)}{2}+\frac{\left(\sigma_{x}-\sigma_{y}\right)}{2} \cos 2 \theta+\tau_{x y} \sin 2 \theta
$$

\subsection{Experimental set-up}

The experimental set-up of the hole drilling technique consists of different items which are interconnected with each other. Essentially, there must be one hole drilling apparatus for drilling the hole in the specimen, strain gauges around the hole to measure the relieved strain, data acquisition system to record the relived strain in the form of micro-strain $(\mu \varepsilon)$ and proper power 


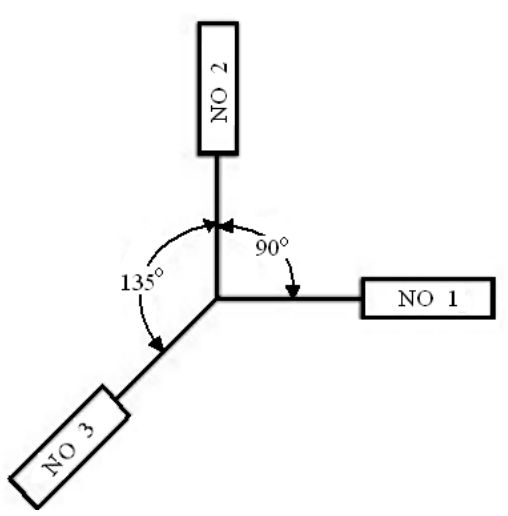

Fig. 2 Strain gauges' angle orientation

supply to activate data acquisition system. Strain gauges are bonded on the specimen and terminals of the gauges are connected with data acquisition system.

The working principle of this method is based on the introduction of a very small hole into a residually stressed element due to which the stress at that location is relaxed. This relaxation changes the stress-pattern in the immediately surrounding area of the drilled hole and the relieved strain on the surface around the hole of the test object is ${ }^{28)}$ displayed in the monitor through data acquisition system. The hole-drilling technique for measuring residual stress around the hole by a mechanical extensometer was first introduced by Josef Mathar ${ }^{29)}$ in 1934 and his observations in the form a paper was published posthumously in the Transactions of the American Society of Mechanical Engineers.

\subsection{Assumptions \& considerations for uniform stress measurement}

The measurement of residual stress by the computation of thermo-mechanical-elasto-plastic strain parameters by hole-drilling technique is dependent on some important considerations, like a) the material should be isotropic in nature and b) the mechanical properties as

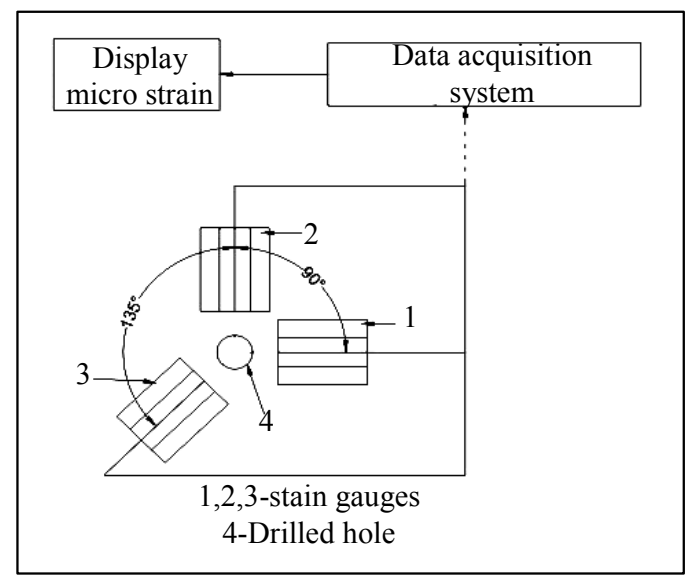

Fig. 3 Experimental set-up

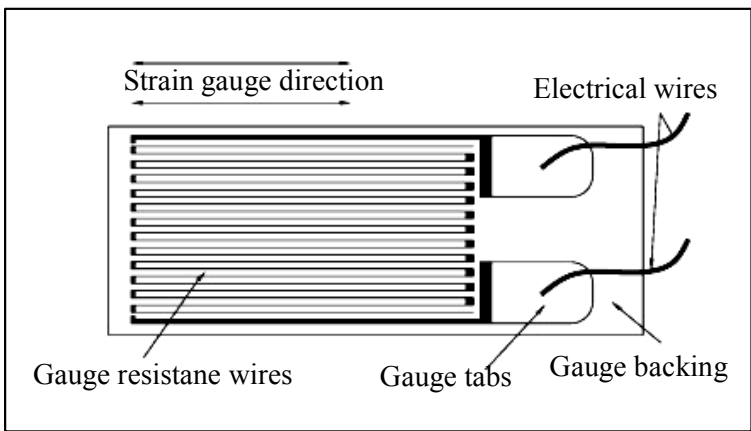

Fig. 4 A typical strain gauge

required for such computation should be properly known and c) drilling a hole at the desired position is possible. Further, additional care should be taken to control the noise at minimum level in order to avoid its interference during measurement. It is beneficial to drill the hole near to the weld centre line, within heat affected zone (HAZ), for obtaining the effective tensile residual stress magnitude, as the nature of stress is changed from tensile to compressive with the increase in distance from weld centre line.

\subsection{Application and selection of strain gauges with placement procedures}

Application of strain gauges to measure the relieved strain in the field of hole drilling method was first introduced by W.Soette and R.Vancrombrugge ${ }^{30)}$ together in 1950 based on the fundamental working principle of strain gauge. The mostly considered parameters for selecting strain gauge are a) Gauge factor of the strain gauge b) Gauge width and gauge length of the strain gauge c) Resistance of each gauge element d) Backing material of strain gauge e) Temperature of the applied field

It is equally important to prepare the surface in the correct way and the strain gauge should be pasted on the surface of the specimen ${ }^{31)}$ using appropriate adhesive, as recommended by the manufacturer. Ideally, the surface of the test material should be flat and the hole location should not be nearer to any edge to avoid any error in data. Three separate uniaxial strain gauges may be fixed on the surface around the hole to be drilled, in a rosette pattern, to get the radial strain readings $\varepsilon_{1}, \varepsilon_{2}, \varepsilon_{3}$ in three directions. As per ASTM standard, ${ }^{3)}$ the size of the drill should maintain the following relationship:

$$
2.5<\mathrm{D} / \mathrm{D} 0<3.4
$$

Where $\mathrm{D}$ is the diameter of the gauge circle and $\mathrm{D}_{0}$ is the diameter of the drilled hole. The design of strain gauge rosette has been extended with the introduction 
of 8-gauge design ${ }^{32}$, 12-gauge design and 6-gauge ${ }^{33)}$ design in the applied field for obtaining better measurement results. but 3-gauge rosette design has been given preference to other design due to simple orientation and less cost.

\subsection{Strain gauge data collection}

The output of strain gauge is generally obtained in the form of micro-strain $(\mu \varepsilon)$ from the multichannel data acquisition system. Strain gauge may become a part of wheatstone bridge circuit in the form of quarter bridge, half bridge or full bridge where the sensitivity of the later one is twice that of the former one ${ }^{34-36)}$. As and when the through hole in the specimen is done with the suitable drill, the released strain is recorded and the related stress can be calculated,accordingly. However, the use of small depth increment during drilling in the specimen up to full depth ${ }^{25}$ has been suggested by ASTM E837 for obtaining more precision in the measurement $^{26)}$.

\subsection{Blind hole complexity}

Few experiments have been carried out incorporating blind hole in the plate instead of through hole, but satisfactory outcome has not been achieved as the blind hole shape and subsequent stress strain relationship was found complex for further computation and the same was observed by Kelsey ${ }^{37)}$ in 1956. Rendler and Vigness ${ }^{38)}$ have examined both blind hole \& through hole condition in the experimental plates, in 1966, and investigated the distribution of relieved stress pattern in both cases. They observed that stress distribution in blind hole condition, as shown in Fig. 5, was critically close to the through hole condition up to a certain level. They introduced the coefficients $\bar{A}$ and $\bar{B}$ as geometric functions of modulus of elasticity (E) and Poisson's ratio $(\mu)$ for the materials in use. The following expressions were formed with new variables $E$, v and Z/D to define $\bar{A}$ and $\bar{B}$.

$$
\begin{gathered}
\bar{A}=\mathrm{fA}(\mathrm{E}, \mathrm{v}, \mathrm{r}, \mathrm{Z} / \mathrm{D}) \\
\bar{B}=\mathrm{fB}(\mathrm{E}, \mathrm{v}, \mathrm{r}, \mathrm{Z} / \mathrm{D})
\end{gathered}
$$

where $r=R / R_{o},\left(R \geq R_{o}\right), R=$ Radius of the gauge circle $\& R_{o}=$ Radius of the drilled hole, $Z / D=$ Ratio of blind hole depth to strain gauge pitch circle diameter (dimensionless).

However, the local yielding ${ }^{39,40)}$ may take place due to high stress concentration around the hole and it affects significantly in stress calculation when the magnitude of residual stresses lies in between 60 percent to 70 percent of the yield strength ${ }^{41)}$ of the material in consideration.

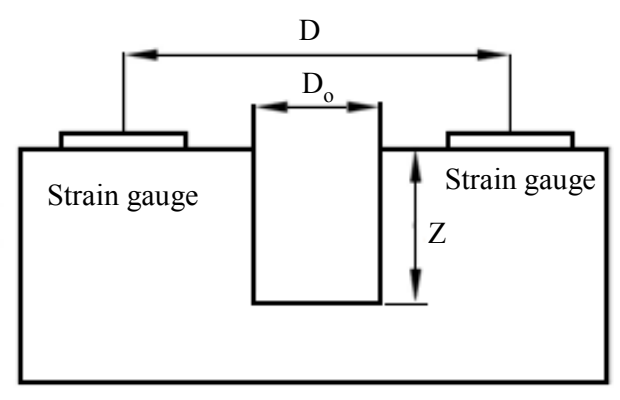

Fig. 5 Blind hole geometry

\subsection{Influence of hole eccentricity and high speed drill}

It reveals from different experimental observations of the hole drilling measurement technique that hole eccentricity and size throughout the specimen contribute a significant changes in the value of strain. The eccentricity in the drilled hole induces error in the measurement of residual stress ${ }^{42-45)}$ and in some cases, by using optical alignment the eccentricity can be minimized. In line with this, Rendler \& Vigness $3^{8)}$, conducted many experiments and observed that the accuracy of the hole drilling method was influenced mainly by two factors viz. 1) Improper fixation of drill at the appropriate point and 2)Eccentricity developed in the drilled hole due to wrongly adopted drilling technique. The use of abrasive jet machining (AJM) for making stress-free holes has been tested by Bush and Kromer ${ }^{46)}$ in 1972, and later, by Procter and Beaney ${ }^{47)}$, and by Bynum ${ }^{48)}$ in 1974 where satisfactory outcome could not be achieved due to some limitations. Though stress free holes were found possible to generate in virtually all materials but its chief limitation was lying in the changing of hole shape, specially tapering of holes with the increase of depth of hole as depicted in Fig. 6. Furthermore, the total set-up is very complex, costly $\&$ not portable which ultimately has made AJM a less suitable technique for measuring relieved strain by hole drilling technique.

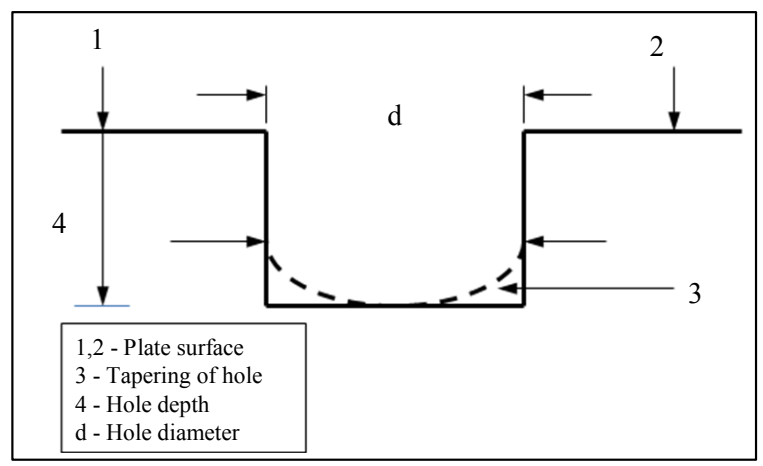

Fig. 6 Tapering of hole 
In the way of upgrading the measurement process for obtaining better result, hole drilling technique with high rpm has been introduced to reduce the additional stress induced by the drilling process itself ${ }^{49)}$. Though the technique has the several advantages like better accuracy in result, less induced-stress by the process but the frequent tool wear is a major disadvantage. Such wear in tool during operation may invite significant measurement errors $^{50)}$ and removal of broken tool from the specimen is not easy. In 1982, Flaman ${ }^{51)}$ first used a high-speed (up to $400000 \mathrm{rpm}$ ) air turbine with an attachment of carbide cutter for drilling the hole in the specimen. But, this technique has not been adopted widely in the practical field due to non-availability of such experimental set-up and high cost involvement with this. As a part of alternative approach, the electric discharge machining (EDM) process has been introduced in the field of measurement, for making highly precise holes on various metals. In the investigation process based on EDM by Ghanem et al. ${ }^{52)}$, it is observed that a tensile residual stress is generated within the EDM transformation layer. Ekmekci et al. ${ }^{53)}$ conducted different experiments to investigate the influence of dielectric fluids and electrode on residual stress with various EDM parameters and developed an empirical relationship between residual stresses and EDM parameters. Olabi and Hashmi ${ }^{54,55)}$ used the hole drilling method to investigate the magnitude and distribution of residual stresses in high-chromium steel. Liuet al. ${ }^{56)}$ have conducted the experiments on thick aluminum plates to understand the nature of residual stress distribution by this method. Schajer, Flaman, Ajovalasit and other investigators ${ }^{57-60)}$ have conducted several experiments with uniform and non-uniform stress field by hole drilling method. Introduction of finite element method (FEM) in the measurement field has considerably increased the accuracy, particularly in non-uniform stress field. Power series method, a modified approach of integral method, has been used by Schajer based on some specific assumptions where stress magnitude changes with respect to depth. L.R. Lothhammer et al. $^{61)}$ conducted the experiments on the UOE and ERW pipes to investigate the nature of residual stress developed on the outer and inner surfaces of the pipelines by the DSPI hole drilling combined technique and traditional hole drilling technique. Results on UOE pipes and ERW pipes were compared and it was observed that the first half of the longitudinal and circumferential stress profile was compressive in nature while the later half revealed the tensile residual stress, in both the cases.

\section{Summary and Conclusions}

It reveals from the preceding discussion that the hole drilling strain gauge method is a widely acceptable destructive process, in the industry as well as in the academic field, to find out the welding residual stress for its low equipment cost, versatility and reasonable accuracy and standardized by ASTM E- 837 .

The advantages of traditional hole drilling method include the following:

1) The method can be used on large components at site as the related equipments are portable

2) The actual test is quick and inexpensive and can be done on a wide range of materials including polymeric samples

3) The test can be carried out on curved or flat surfaces

4) The process is suitable for both uniform and nonuniform stress field

5) It is possible to quantify the principal residual stresses along the depth of hole of the specimen

6) The technique is acceptable worldwide and standardized by ASTM E-837.

It appears that application of strain gauge hole drilling technique is significant in the field of residual stress measurement and substantial work can be carried out with this method. However, precautions on some parameters have to be taken into consideration so that noise level can be minimized. Today, the rapid development of different software pertaining to this field has made the process more accurate with high speed computational ability through which the simulation of the stress field distribution is possible taking proper thermo physical parameters in consideration.

ORCID: R.Chakrabarti: https://orcid.org/0000-0002-2128-2014 ORCID: P. Biswas: https://orcid.org/0000-0001-7069-0308

\section{References}

1. Khanna, O.P., A Text Book of Welding Technology, Dhanpat Rai publications (p) limited, New Delhi-110002

2. Radhakrishnan, V.M., Welding Technology \& Design, New Age International (P) Limited publishers, Delhi110002

3. Parmar, R.S., Welding Engineering and Technology, Khanna publishers, Delhi-110006

4. P.J.Withers, H.K.D.H.Bhadeshia, Overview Residual Stress Part 2 - Nature and Origins, Materials Science and Technology, April, 17(2001), 366-375 https://doi.org/10.1179/026708301101510087

5. A. W.HUBER\&L. S. BEEDLE, Residual Stresses and the Compressive Strength of Steel, Welding Journal, 33 (12) (1954), 589-614

6. Radaj, Dieter, Heat Effects of welding, Springer-Verlag, 
$15-67$

https://doi.org/10.1007/978-3-642-48640-1

7. N. S. Rossini, M. Dassisti, K. Y. Benyounis and A. G. Olabi, Review of Methods for Measuring Residual Stresses in Components, Materials and Design, January (2011), $1-40$

https://doi.org/10.1016/j.matdes.2011.08.022

8. Koichi Masubuchi \& D. C. Martin, Investigation of Residual Stresses in Steel Weldments, SSC-174, Project SR-167, 60-75

9. N. Tebedge, G. Alpsten, L. Tall, Residual-stress measurement by the sectioning method, Exp. Mech, 13(2) (1973), $88-96$

https://doi.org/10.1007/BF02322389

10. M.B Prime, A.R Gonzales, Proceedings of the sixth international conference on residual stresses, Oxford, UK: IOM Communications Ltd, (2000), 617-624

11. N. Murugan, R. Narayanan, Finite element simulation of residual stresses and their measurement by contour method, Materials and Design, 30(6) (2009), 2067-2071 https://doi.org/10.1016/j.matdes.2008.08.041

12. M.B. Prime, Residual stress measurement by successive extension of a slot, the crack compliance method, Appl. Mech Rev, 52(2) (1999), 75-96 https://doi.org/10.1115/1.3098926

13. W. Cheng, I. Finnie, Residual stress measurement and the slitting method, NewYork, Springer (2007) https://doi.org/10.1007/978-0-387-39030-7

14. K.P. Milbradt, Ring-method determination of residual stresses, Proc SESA, 9(1) (1951), 63-74

15. S. Kiel, Experimental determination of residual streses with the ring-core method and an onlinemeasuring system, Exp Tech, 16(5) (1992), 17-24 https://doi.org/10.1111/j.1747-1567.1992.tb00701.x

16. J. H. Norton and D. Rosenthal, Stress measurement by $\mathrm{x}$-ray diffraction, Proceedings of the society for experimental stress analysis, 1(2) (1944), 73-76

17. J. H. Norton and D. Rosenthal, Application of the X-ray method of stress measurement to problems involving residual stress in metals, Proceedings of the society for experimental stress analysis, 1(2) (1944), 81-90

18. Seok-Hoon Kim, Jong-Bum Kim, Won-Jae Lee, Numerical prediction and neutron diffraction measurement of the residual stresses for a modified $9 \mathrm{Cr}-1 \mathrm{Mo}$ steel weld, Journal of Materials Processing Technology, 209(8) (2009), 3905-3913 https://doi.org/10.1016/j.jmatprotec.2008.09.012

19. G.A. Webster (Ed.), Polycrystalline materials - determinations of residual stresses by neutron diffraction, ISO/TTA3 Technology Trends Assessment, Geneva 20, Switzerland, (2001)

20. F. Balahcene, J. Lu, Study of residual stress induced in welded steel by surface longitudinal ultrasonic method, Proceedings of SEM Annual Conference on Theoretical, Experimental and Computational Mechanics, (1999), 331-
334

21. Y. Kudryavtev, J. Kleiman, O. Gushcha, V. Smilenko, V. Brodovy, Ultrasonic technique anddevice for residual stress measurement, $X$ Int. Congress and Exposition on Experimental and Applied Mechanics, (2004), 1-7

22. Roy, A.K, Use of Positron Annihilation Spectroscopy for Stress-Strain Measurements, Transmutation Sciences Materials (TRP), (2005), 32-33

23. D. M. Stewart, K. J. Stevens, A. B. Kaiser, Magnetic Barkhausen noise analysis of stress in steel, Original Research Article Current Applied Physics, 4 (2-4) (2004), 308-311 https://doi.org/10.1016/j.cap.2003.11.035

24. H. IlkerYelbay, Ibrahim Cam, C. HakanGur, Non-destructive determination of residual stress state in steel weldments by Magnetic Barkhausen Noise technique, NDT\&E International, 43 (2010), 29-33 https://doi.org/10.1016/j.ndteint.2009.08.003

25. ASTM E 837-01, Standard Test Method for Determining Residual Stresses by the Hole-Drilling Strain Gage Method., American Society for Testing and Materials, October, (2001) https://doi.org/10.1520/E0837-01

26. ASTM Standard Test Method E837-08, Determining Residual Stresses by the Hole-Drilling Strain-Gage Method, American Society for Testing and Materials, West Conshohocken, PA. (2008)

27. Bhandari, V B, Design of Machine Elements, Tata Mcgraw Hill Education Private Limited, New Delhi., $3^{\text {rd }}$ Edition, 104-112

28. Vishay Measurements Group, Inc., Measurement of Residual Stresses by the Hole Drilling Strain-Gage Method, Technical Note TN-503-6, Vishay Measurements Group, Inc., Raleigh, NC, (1996)

29. Mathar, J., Determination of Initial Stresses by Measuring the Deformation Around Drilled Holes, Transactions ASME, 56 (4) (1934), 249-254

30. Soete, W. and Vancrombrugge, R, An Industrial Method for the Determination of Residual Stresses, Proceedings SESA, 8(1) (1950), 17-28

31. Perry C.C. and LissnerH.R, THE STRAIN GAGE PRIMER, McGraw-Hill, Inc., New York, (1962)

32. Grant, P. V., Lord, J. D. and Whitehead, P. S., The Measurement of Residual Stresses by the Incremental Hole Drilling Technique, Measurement Good Practice Guide, 53(2), National Physical Laboratory, Teddington, UK, (2002)

33. Tootonian, M and Schajer, G.S., Enhanced Sensitivity Residual Stress Measurements using Taper Hole Drilling, Experimental Mechanics, June, (1995), 124-129 https://doi.org/10.1007/BF02326469

34. Sirohi R.S, Mechanical measurement, New Age International $(P)$ Ltd, $2^{\text {nd }}$ edition, 75-114

35. Rajput R.K, Mechanical Measurement and Instrumentation, S.K.Kataria\& Sons, $1^{\text {st }}$ Edition, Reprint-2011, 614- 
640

36. Ernest O Doebelin, Dhanesh N Manik, Measurement systems application and design, Tata Mcgraw Hill Education Private Limited, New Delhi., 150-185

37. Kelsey, R.A., Measuring Non-uniform Residual Stresses by the Hole-Drilling Method, Proc., SESA XIV, 1, 181194

38. Rendler, N.J. \&I. Vigness, Hole-Drilling Strain Gage Method of Measuring Residual Stress, Proc., SESA XXIII, 2 (1966), 577-586

39. Flaman, M.T. and B.H. Manning, Determination of Residual Stress Variation with Depth by the HoleDrilling Method, Experimental Mechanics, 25(1985), 205-207 https://doi.org/10.1007/BF02325088

40. Measurement of Residual Stresses by the Hole-drilling Strain Gage Method, Technical Note No. TN-503-4, Vishay-Measurements Group Inc., (1993), 1-19

41. Nobre J. P, KornmeierM., Dias A. M. and Scholtes B, Use of the Hole-drilling Method for Measuring Residual Stresses in Highly Stressed Shot-peened Surfaces, Experimental Mechanics, September, 40(3) (2000), 289297

https://doi.org/10.1007/BF02327502

42. KarelSva “ r' 1 cek, Milo`sVlk, Residual stress evaluation by the hole-drilling method with eccentric hole", Engineering MECHANICS, 14 (1) (2007), 191-197

43. Ajovalasit A., Measurement of Residual Stresses by Hole Drilling Method: Influence of Hole Eccentricity, Journal of Strain Analysis, 14(4) (1979), 171-178 https://doi.org/10.1243/03093247V144171

44. Wang H.C., The Alignment of the Hole-Drilling Method, Experimental Mechanics, 17 (1979), 23-27 https://doi.org/10.1007/BF02327766

45. Paul Barsanescu, Petru Carlescu., Residual Stress Measurement by the Hole-Drilling Strain-Gage Method: Influence of Hole Eccentricity, http://www.researchgate.net/ publication, January, (2007)

46. Bush, A.J. and F.J. Kromer, Simplification of the Hole drilling Method of Residual Stress Measurements, Trans., ISA 112, 3 (1973), 249-260

47. Procter, E. and E.M. Beaney, Recent Developments in Centre-hole Technique for Residual-stress Measurement, Experimental Techniques, December , 6 (1982), 10-15 https://doi.org/10.1111/j.1747-1567.1982.tb02066.x

48. Bynum, J.E., Modifications to the Hole-drilling Technique of Measuring Residual Stresses for Improved Accuracy and Reproducibility, Experimental Mechanics, January, 21 (1981), 21-33 https://doi.org/10.1007/BF02325923

49. M.T. Flaman, G.A. Herring, Comparison of four holeproducing techniques for the center-holeresidual-stress measurement method, Exp. Tech, 9 (1985), 30-32 https://doi.org/10.1111/j.1747-1567.1985.tb02036.x

50. M.T. Flaman, G.A. Herring, Ultra-high-speed centerhole technique for difficult machining Materials, Exp.
Tech, 10 (1986), 34-35

https://doi.org/10.1111/j.1747-1567.1986.tb01370.x

51. Flaman, M.T., Brief Investigation of Induced Drilling Stresses in the Center-hole Method of Residual-stress Measurement, Experimental Mechanics, January, 22 (1982), 26-30 https://doi.org/10.1007/BF02325700

52. F. Ghanem, C. Braham, H. Sidhom, Influence of steel type on electrical discharge machined surface integrity, Journal of materials processing technology, 142 (2003), 163-173

https://doi.org/10.1016/S0924-0136(03)00572-7

53. B. Ekmekci, A.E. Tekkaya, A. Erden, A semi-empirical approach for residual stresses in electric discharge machining (EDM), Int. J. Mach. Tools Manufacturing, 46 (2006), 858-868 https://doi.org/10.1016/j.ijmachtools.2005.07.020

54. A.G. Olabi, M.S.J. Hashmi, The effect of post-weld heattreatment on mechanical-properties and residual-stresses mapping in welded structural steel, Journal of Materials Processing Technology, 55 (1995), 117-122 https://doi.org/10.1016/0924-0136(95)01794-1

55. A.G. Olabi, M.S.J. Hashmi, Stress relief procedures for low carbon steel (1020) welded Components, Journal of Materials Processing Technology, 56 (1996), 552-562 https://doi.org/10.1016/0924-0136(95)01869-7

56. J. Liu, H. Zhu, W. Xu, Analysis of residual stresses in thick aluminum friction stir welded butt joints. Materials and Design, 32(4) (2011), 2000-2005 https://doi.org/10.1016/j.matdes.2010.11.062

57. Schajer, G.S., Measurement of Non-Uniform Residual Stresses Using the Hole Drilling Method, Journal of Engineering Materials and Technology, 110(4), Part I, 338-343; Part II, 344-349 https://doi.org/10.1115/1.3226059

58. Flaman, M.T., Mills B.E., and Boag J.M., Analysis of Stress-Variation-With-Depth Measurement Procedures for the Centre Hole Method of Residual Stress Measurements, Experimental Techniques, June, 11 (1987), $35-37$ https://doi.org/10.1111/j.1747-1567.1987.tb00422.x

59. Ajovalasit, A., Measurement of Residual Stresses by the Hole-Drilling Method: Influence of Hole Eccentricity, Journal of Strain Analysis, 14(4) (1979), 171-178 https://doi.org/10.1243/03093247V144171

60. Beaney, E.M. and E. Procter, A Critical Evaluation of the Centre-hole Technique for the Measurement of Residual Stresses, Journal of BSSM, 10(1) (1974), 7-14 https://doi.org/10.1111/j.1475-1305.1974.tb00074.x

61. Livia R. Lothhammer, Matias R. Viotti, Armando Albertazzi Jr., Celso L.N. Veiga, Residual stress measurements in steel pipes using DSPI and the hole drilling technique, International Journal of Pressure Vessels and Piping, 152 (2017), 46-55 https://doi.org/10.1016/j.ijpvp.2017.05.008 